\title{
Habitar el privilegio: relaciones sociales en los fraccionamientos cerrados en Guadalajara
}

\author{
MANUELA CAMUS
}

En esta exposición se perfilan las relaciones sociales y las representaciones del privilegio en las voces de los residentes de los fraccionamientos cerrados de elite en Guadalajara. Se quiere mostrar cómo estos lugares están constituyendo y reforzando una visión y una práctica de orden colonial estamental, que se reproduce y naturaliza en otros sectores sociales, lo que habla de una inquietante valoración positiva del privilegio y la jerarquía.

PALABRAS CLAVE: fraccionamientos cerrados, privilegio, relaciones sociales, desigualdad, proceso de estamentación

Inhabiting the Privilege: Social Relations within the Gated Communities in Guadalajara

This article reviews the social relations and the representations of the privilege in the voices of residents of the elite's gated communities in Guadalajara. It pretends to show how they are forming and reinforcing a vision and a practice of an estates colonial society that can be reproduced and naturalized in other social sectors, which speaks about a disturbing appreciation of privilege and hierarchy.

KEYWORDS: gated communities, privilege, social relations, inequality, estates society 


\section{El éxito de la "cotificación"}

os fraccionamientos residenciales privados exclusivos, llamados cotos en Guadalajara, son un enérgico símbolo espacial de la configuración actual del capitalismo y su poder, y del paradigma de la privatización de los espacios públicos y la secesión social (Low, 2003; Caldeira, 2007; Svampa, 2008). ${ }^{1}$ Las capas sociales que los habitan intentan establecer su orden y certidumbre ante la desconfianza en el poder regulador del Estado y la gestión pública de las ciudades, y frente a la polarización social acrecentada por las políticas neoliberales y su conciencia del resentimiento social. Por ello, su detonante en la década de 1990 se vincula al clima de miedo e inseguridad que se establece y responde a una estrategia de las capas medias altas y altas para autoprotegerse y resguardar su patrimonio y lo colectivo interno.

Habitar en cotos ha sido un modelo socialmente construido, pero también diseñado y potenciado por las desarrolladoras inmobiliarias que, con sus discursos y mercadotecnia, aprovechan la preocupación por la inseguridad y logran imponerlo como la forma deseable de residir, no sólo para las elites. ${ }^{2}$ Su fórmula ha fascinado el imaginario de grandes sectores sociales al combinar seguridad, éxito y familia en comunidad-aislamiento, lo que conforma todo un acontecimiento sociocultural.

$1 \quad$ Los cotos son urbanizaciones con un muro perimetral y entradas controladas que, bajo el régimen de condominio, comparten áreas y servicios comunes: seguridad, casa club, espacios deportivos y de recreo, áreas verdes. Son formas mixtas de propiedad que incorporan propiedad privada, propiedades en común y servicios propios que los vecinos deben autogestionar por medio de las juntas de condóminos. Al ser autónomos respecto a las autoridades municipales, crean reglamentos propios y establecen pagos y cuotas de mantenimiento.

2 Entiendo las elites en un sentido sociocultural de grupos minoritarios privilegiados con riqueza, autoridad e influencia que activan estrategias culturales para representarse, reproducirse, asentar su comunidad moral, mostrar su estatus y desarrollar así su dominación (Shore, 2002). Me referiré a ellas, en un sentido amplio, como sectores acomodados y clases medias altas y altas. 
Desde la configuración espacial de los cotos, sus habitantes muestran el tipo de vínculos que quieren establecer con la sociedad, el Estado y las autoridades, que consienten esta actitud y práctica de apartamiento en un contexto de supremacía del mercado. Todos comparten valores conservadores, como la recreación de la familia nuclear, la acérrima defensa de la propiedad privada y un estilo de vida en el que ejercen ese "buen vivir" con base en su autosegregación (Arizaga, 2005). Su capacidad de consumo les permite acceder a una educación bilingüe y sistemas de salud privados, servicios que reproducen sus prerrogativas.

Los condominios cerrados de elite ofrecen un ideal de ascenso social, estatus y plusvalía — palabra recurrente entre los propietarios-; así, un eslogan promocional ofrece "El privilegio de vivir por encima de los demás". Los cotos incorporan grupos privilegiados heterogéneos que representan a "los ganadores" de la globalización: miembros de la burguesía, nuevos ricos, oligarcas tradicionales, elites políticas, clases emergentes nacionales y transnacionales - entre ellos, criminales-, y otros, procedentes de profesiones llamadas clásicas. Maristella Svampa se atreve a definir su autodefensa como "impunidad de clase", es decir, revierten su pretendida protección para marcar cómo hacen valer su poder y distinción (2008).

Los conjuntos residenciales cerrados han sido estudiados en abundancia en muchos países, también en México, con atención especial a efectos sobre el urbanismo y la sustentabilidad de la ciudad, la segregación social y las percepciones de inseguridad y miedo. ${ }^{3}$ En este caso, el interés se dirige a las relaciones sociales y la concepción de lo social de sus residentes. Los testimonios proceden de una investigación realizada en Guadalajara entre 2010 y 2014, en la que se recogieron las dinámicas cotidianas de varios tipos de coto de clases medias altas y altas, en las voces de las mujeres residentes (Camus, 2015). ${ }^{4}$
Con el apoyo de alumnos de la licenciatura de antropología de la Universidad de Guadalajara, durante en 2016 y 2017, se amplió la gama de fraccionamientos cerrados, para advertir cómo se asumía este modelo de habitar la ciudad en otros sectores sociales. Retomaré uno de esos casos al final de esta exposición.

El municipio de Zapopan, parte del Área Metropolitana de Guadalajara, contiene la mayoría de los cotos de elite. Se sitúa sobre ejes de acceso a la ciudad, cruzado por el anillo periférico, y disfruta de condiciones ambientales especiales por la proximidad del Bosque La Primavera y el parque de Los Colomos (Cabrales y Canosa, 2002). Entre los cotos de lujo, identifiqué tres categorías. $\mathrm{Ca}-$ da una supone un perfil sociocultural y problemas particulares. Los conjuntos estándar, como Parque Regency, suelen ser de adosados y corresponden a diseños de viviendas ya elaborados. Los campestres — por ejemplo, Rancho Contento- se caracterizan por asomarse a "los espacios naturales"; en éstos suelen converger elites intelectuales y sus moradores manifiestan con más fuerza las críticas a su opción de vida. Los de prestigio, como Valle Real, se distinguen porque los terrenos son más amplios y los propietarios decidieron, por lo regular, el diseño de sus residencias. Cada coto tiene un estatus y las urbanizadoras los promocionan en mercados específicos:

3

Su expansión se observa en buena parte del globo y se han implantado en tradiciones culturales específicas (Low, 2003).

4 Se señala que los debates sobre los cotos están prejuiciados, que se alcanzan "verdades simplificadas", muchas veces sin pruebas empíricas (Janoschka y Glasze, 2003). Como en toda investigación, se escucha, lee, observa y se va conociendo. Agradezco la generosidad de las mujeres que me abrieron la puerta de sus vidas y residencias. La valoración posterior de lo aprendido e interpretado sobre la generalidad de los casos ha buscado ser ecuánime pero también crítica. 
Puerta de Hierro, para nuevos ricos; familiares, en las colonias Seattle y Altamira; glamorosos, como El Cielo y El Río; bohemios, como Guayabos; de familias de abolengo, como San Miguel de la Colina. A éstos se suma la proliferación reciente de condominios verticales, que introducen sus particularidades en cuanto a sector social, convivencias y conflictos.

Los cotos comparten las estrategias simbólicas de autorrepresentación y promoción de la supremacía y el privilegio, que van desde cercar el perímetro hasta los diseños internos del residencial o la grandilocuencia de los arcos de entrada. Los nombres, con ecos nostálgicos de corte monárquico, como Valle Real o Parque Regency, de evocación sacra y paradisiaca en Campos Elíseos, o que expresan la domesticación de la naturaleza, como Villas del Pinar o Quinta Los Encinos, corresponden a la concepción ideológica conservadora que acuña este modo de vida que simula una raigambre aristocrática. Bajo estas formas estéticas, expresan su deseada distinción y su estilo de vida cómodo, despegado y ajeno al resto, entre el consumo y una sociabilidad previsible. Esta estética tiene una fuerte carga política porque busca "normalizar el estado de emergencia” (Rojas, 2007: 16).

Los residentes de los cotos viven en un "como si" no fueran parte de la metrópoli, lo que incorpora un sinnúmero de contradicciones (Duhau y Giglia, 2008). Hay paradojas entre el encierro y el "para todo hay que salir"; entre la experiencia de sociabilidad infantil de "el coto como nana", por la importancia que dan a los niños, y la experiencia de lo que era "la calle" o el encerramiento en el que se convierte para los adolescentes; entre el discurso de opción por una vida verde y la dependencia extrema del coche, o bien, entre cómo se organiza su heterogeneidad interna mientras se produce una simplificación social extrema entre los que sirven y los servidos (Camus, 2015).
Además, plantean una relación específica entre espacio público y privado, y entre ellos, como privilegiados, y el resto de la sociedad. Así, muestran una alta consideración y respeto por lo propio colectivo interno, pero no tanto por lo público, que sienten apropiable. Patricia Safa y Juan Manuel Ramírez ya observaban que "lo que suceda fuera de esa barda les interesa muy poco” (2011: 134).

Hay muchachos que salen, van en las cuatrimotos y las cuatrimotos también deben respetar la velocidad de $30 \mathrm{~km} / \mathrm{h}$ o no subirse a los camellones. Es por el bienestar de nosotros mismos. Y te vas acostumbrando, y tienes que hacerlo por ti y por tus hijos, tienes que poner el ejemplo. Tienes que cooperar para ser mejor ciudadano. ¡No es lo mismo una cuatrimoto en La Primavera o en el campo traviesa que aquí! (entrevista con empresario, Valle Real, coto de lujo, 24 de junio de 2010).

Esta exposición trata, en un primer apartado, las relaciones sociales y las representaciones del privilegio expresadas por los residentes de los fraccionamientos cerrados de elite en Guadalajara. Después, muestra cómo este modelo de hábitat está constituyendo y reforzando una visión y una práctica estamentarias de lo social, que se reproduce en otros sectores sociales. El artículo resalta los lugares comunes sobre este estilo de vida para advertir su normalización y sus consecuencias: la hegemonía de una valoración positiva de la preeminencia y la jerarquía.

\section{Relaciones sociales intra y extramuros}

A continuación, se hace un perfil de las relaciones sociales que se establecen en estos espacios cercados por medio de los testimonios de los residentes, que ofrecen su cosmovisión, el sentido que dan a su experiencia y su entendimiento del mundo y la sociedad. 


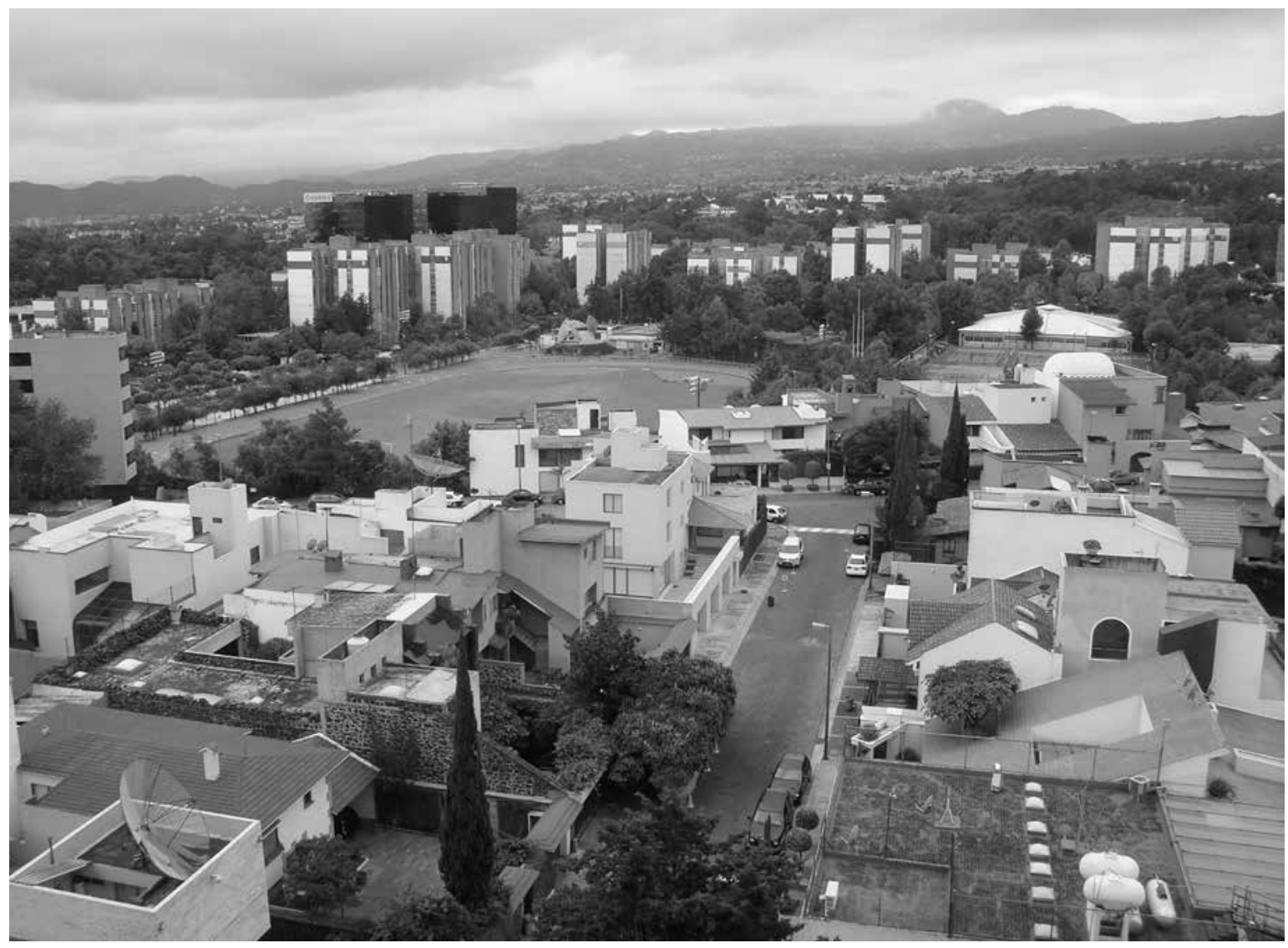

LUCY NiETo • Uno de los primeros fraccionamientos cerrados de elite al sur de la Ciudad de México. Al fondo, el conjunto de condominios Villa Olímpica, octubre de 2008.

\section{LA AUTOSEGREGACIÓN O EL GUETO POR OPCIÓN}

En estos cotos hay un esfuerzo discursivo por representarse como la utopía de la comunidad armónica, igualitaria, solidaria entre la "gente como uno" o GCU: "el espacio es muy familiar, hay un ambiente de confianza, sabes con quienes estás viviendo, no es como que te vas a encontrar un desconocido en la calle" (entrevista con mujer residente, Jardín Real, coto estándar, 24 de octubre de 2016).

Estos residentes proponen de nuevo una relación distinta entre los ejes público y privado, con la emergencia de una "ciudadanía patrimonialista”, en la que imponen sus criterios por su poder económico y se permiten prescindir del Estado y las autoridades públicas (Svampa, 2008). Es una ciudadanía restringida que desarrolla una reglamentación interna excesiva, que en ocasiones transgrede las leyes externas y las libertades individuales de los otros no iguales, como veremos. Incluso entre ellos "siempre hay diferencias internas, algunos vecinos tienen privilegios, a ellos no les dicen nada y a otros sí” (entrevista con arquitecta, Ciudad Granja, coto estándar, 5 de enero de 2010).

De hecho, las relaciones internas se asocian a la cobertura puntual por cada vivienda de las cuotas para servicios comunes. Los vecinos morosos anticomunitarios se ponen en evidencia al negarles la 
tarjeta con chip que da acceso automático, al anotar sus nombres y apellidos en la pizarra de entrada o imponer el pago de infracciones. Como medidas extremas, la presión que el colectivo ejerce es el ostracismo, la expulsión de "la comunidad":

Es un lugar exclusivo, no cualquiera puede entrar al coto. Además, se paga para el mantenimiento, y si no pagas, no se te permite la entrada a tu casa ni la renta del local de eventos y mucho menos el mantenimiento a tu casa, ya sea el fontanero o el jardinero [que] son contratados por la misma administración del coto (entrevista con mujer joven, Quintas de La Soberana, coto estándar, 2 de mayo de 2017).

El coto es un mecanismo de protección para sus habitantes. Cuenta con dispositivos sofisticados de control de entrada y salida de personas para filtrar las amenazas del exterior y el paso del transporte público. La voz crítica de Susi señala:

El que tu carro tenga pegada una cosita que te permita salir y entrar, pues jigual me llevan en la cajuela a mí y a toda mi familia! Allí están los policías, tienen registrado en la computadora con cámara a qué hora entras y a qué hora sales, si ellos quieren robarte o se quieren meter a tu casa a comer o a bañarse o acostarse. El repliegue de la seguridad es una fantasía (entrevista con Susi, trabajadora autónoma, Rancho Contento, coto campestre, 5 de julio de 2012).

Las cámaras de vigilancia no tardan en instalarse en los interiores. Los habitantes muestran que no se fían de sus vecinos "iguales" y se controlan entre sí. Cunde la sospecha y la desconfianza, se pierde aún más libertad e intimidad de forma consentida: "pusieron cámaras y eso ahuyentó a los narcos. Pero siempre tienes la sensación de que "no estoy segura" (entrevista con mujer jubilada, Bugambilias, coto de lujo, 27 de abril de 2017). ${ }^{5}$ Puede ocurrir, como vemos, que "el enemigo" viva adentro. De hecho, ha habido riesgos y conflictos por ser "la guarida" de narcotraficantes, delincuentes de "cuello blanco", gente armada y otros: "ahorita tenemos un propietario que todo el mundo lo odia porque es un naco, es horrible, yo creo que es de la Procuraduría o es un policía o así. Tiene mucho despliegue de fuerza y de poder, muchos guaruras allá afuera, nos da pánico" (entrevista con pequeña empresaria, Rancho Contento, coto campestre, 21 de agosto de 2012). ${ }^{6}$

Los vecinos insisten en una convivencia en el interior de los fraccionamientos, pero lo común es que la relación "sólo [sea] entre hola y adiós" y "charlas cortas" (entrevista con estudiante universitario, Bugambilias, coto de lujo, 2 mayo de 2017). Esta percepción coincide con otras investigaciones; por ejemplo, en un coto exclusivo en Tijuana, la socialización es "poco estrecha y se circunscribe a los buenos modales de presentación y saludo cotidiano" (Enríquez, 2007: 152). La ideología comunitaria obliga a promover actividades en días específicos para representar la sociabilidad interna: Día del Niño, fiestas patrias, Navidad.

Estos grupos diversos que confluyen en los cotos parecen acomodarse entre sí en el actual marco del mercado y el consumo, y "la integración hacia arriba" se impone en estas alianzas de clase (Svampa, 2008). Quienes convergen en los cotos coinciden en estas estrategias cultural-simbólicas de mostrarse, en un esfuerzo continuo por mantener

5 Bauman (2008) expone el dilema de la comunidad en la difícil conciliación entre seguridad y libertad: el precio de la comunidad y su seguridad es perder libertad y al revés. Como hemos visto en noticiarios de todo México, es común la detención de líderes y operadores de los cárteles de la droga en condominios cerrados. Los vecinos que conviven con estos "emprendedores" identifican sus viviendas. Algunos "narcos" poseen cotos propios dentro de cotos más grandes, como los exclusivos Valle Real o Puerta Hierro, en el caso de Guadalajara. 
su posición a la cabeza, su distinción. ${ }^{7}$ Por ejemplo, para navidades, los adornos y luces de las residencias de Valle Real son célebres en Guadalajara, todo un ritual de ostentación:

Hay que ir a ver Navidad, hacen concursos de luces, queman toda la electricidad del mundo y las decoraciones son impresionantes (entrevista con mujer artista, Valle Real, coto de lujo, 13 de abril de 2011).

Si se dan una vuelta a Valle Real por ahí del 15 de diciembre, iqué bruto, es competencia! (entrevista con empresario, Valle Real, coto de lujo, 24 de junio de 2010)

La Navidad me encanta, las luces son famosas aquí, siento que se presta mucho... Sabes que estás seguro porque si pones unas velitas alrededor de la glorieta pues no me las van a robar, si cuelgas un Santa Claus en una mata nadie lo descuelga, y muchos sacan sus adornos (entrevista con mujer profesionista, Valle Real, coto de lujo, 29 de abril de 2011).

Pero vivir en la abundancia incorpora la preocupación de "no responder a los ideales de éxito establecidos por nuestra sociedad" (De Botton, 2004: 8). En los cotos, esta ansiedad por el estatus se manifiesta en la presión que ejercen unos sobre otros, como confiesa Susi:

Si un vecino compra un carrito de golf, de pronto los carritos de golf proliferan, lo mismo sucede con las cuatrimotos, o camionetas, autos de marca o vacaciones. Las familias se esfuerzan para no sentirse por debajo del estándar de los demás, esto los lleva a gastar más allá de sus posibilidades reales, adquirir deudas, y a posteriores problemas financieros (entrevista con Susi, trabajadora autónoma, Rancho Contento, coto campestre, 5 de julio de 2012).

\section{LA SERVIDUMBRE Y LA SIMPLIFICACIÓN SOCIAL}

En las urbanizaciones exclusivas existe un complejo montaje escenográfico que permite la segregación interna dentro de una aparente comunidad homogénea. Ser atendidos y mantener enormes viviendas obliga a los residentes a depender de la servidumbre - empleadas domésticas, guardias, jardineros, cocineras, choferes, caballerangos, enfermeras, asistentes personales - y a reproducirse en esta extrema e inquietante "cristalización de las grandes asimetrías", entre los que son servidos y los que sirven (Svampa, 2008).

Los servicios personales domésticos son una práctica común para la reproducción cotidiana de estos sectores, por eso se configura una cultura de servidumbre de poder y jerarquías desde un entramado ideológico y emocional que suaviza la subordinación (Ray y Qayum, 2009). ${ }^{8}$ En una entrevista realizada por Unda (2011), en la ciudad de Guadalajara, queda plasmada la figura de la servidumbre - “es un trabajador que está ahí para ver qué se te ofrece" - y se expone la naturalidad de mandar y ser servido. Los patrones esperan disciplina, honestidad, lealtad, a cambio de tutela, consideración, afecto, gratitud. Cuando se trata de servicio dentro del hogar, compuesto por lo general por mujeres, muchas veces de origen campesino o indígena, éstas serán "como de la familia” y compartirán las dos partes el mandato cultural e ideológico propio de la

$7 \quad$ La distinción establece el lugar del sujeto en el orden social por medio de la identificación y clasificación de la diversidad de gustos e incorpora lógicas performativas para imponer modas, consumos, símbolos culturales, sobre todo entre las elites, que se entienden como guías legítimas del comportamiento de la sociedad (Bourdieu, 2002).

8 Para estos autores, se trata de un sistema vivo de significados y valores que se experimenta y conforma de manera recíproca. La dominación, dependencia y desigualdad no sólo son toleradas, sino aceptadas por las partes de este orden doméstico y asumidas por la esfera pública. 
sociedad patriarcal y blanca, con valores "familiares" y "religiosos" (Durin, 2017).

El funcionamiento de un régimen de servicios se dirige a partir del sometimiento estricto:

\begin{abstract}
A las seis es la hora en que todos los trabajadores se tienen que ir, tienen que parar, los albañiles, los plomeros, todos los que trabajan en obras, no puede quedarse nadie. Pero las chicas que trabajan en las casas pueden salir a la hora que quieren [o] que las dejemos. Tiene que haber ciertos reglamentos para que pueda vivir uno mejor (entrevista con gestora de bienes raíces, Valle Real, coto de lujo, 13 de marzo de 2011).
\end{abstract}

Estos hogares descubren que los valores tradicionales sobre la servidumbre, refuncionalizada para los tiempos modernos, permanecen definidos en términos de subordinación (Camus y De la O, 2014; Durin, 2017). Una estudiante cuenta lo que ve en su fraccionamiento:

Me ha tocado de que denigran mucho a las señoras del aseo y así. Por ejemplo, cuando es Halloween, pasan los niñitos con dulces, para eso hay muchas que les ponen uniforme y hay otras que nada más escucho que les gritan a media calle: "iPanchita, ya bla, bla, bla!” o "PPanchita, te dije que no los subieras, que no!”. Pues si la vas a regañar, regáñala en tu casa, pero eso es súper común. O de que la señora [va] caminando con el niño y la otra señora en su camioneta: "¡súbelo ya y te vas caminando! Ahí te veo en la casa" (entrevista, Villa Coral, coto estándar, 3 de mayo de 2017).

\section{Salir del coto: la segmentación social}

En la actualidad, la lógica de privatización del espacio público supone, como vimos, la consecuente segregación, pero también la segmentación: cada sector social tiende a usar espacios propios y las posibilidades de interacción de la heterogeneidad social son cada vez menos (Duhau y Giglia, 2008). Podría hablarse de una ciudad de esferas diferenciadas a las que unos tienen acceso y otros no. Aunque residir en un coto no anula otras formas de interacción de sus residentes —en el ámbito laboral, recreativo, familiar-, pues no son autocontenidos, son más controladas y autolimitadas.

Los sujetos de las elites que habitan en los suburbios se mueven en el archipiélago de su cartografía, formado por los puntos de encuentro previsibles que acompañan la expansión de los cotos: centros comerciales, escuelas y universidades privadas, clubes, antros, cafés y otros servicios. En ese tránsito, cruzan en sus automóviles hábitats de otros sectores sociales que tienden a ignorar y evitar, los llaman "lunares negritos" e imaginan a su población como amenazante:

San Juan de Ocotán era un pueblo antes y existía desde hace mucho. En la noche, con mis hijos, no me meto ahí, te roban los tenis. Está feíto ahí, los de Ocotán no nos ven muy bien a los que vivimos aquí (entrevista con mujer, Valle Real, coto de lujo, 12 de mayo de 2011).

Pasando el Trompo Mágico o ya irte a Aviación, esas zonas sí son peligrosas. O sea, te vas un poquito para allá y ya dices: "no manches, me van a secuestrar, me van robar, me van a ofrecer droga". Sí hay muchísima diferencia en cuanto a estatus social, en cuanto locales. Literal, barrio pesado. La verdad, casi nunca salgo caminando fuera de Valle Real, casi siempre voy en carro, pero sí me da miedito. Una, como mujer, sí corre más peligro. Me da cosita, hay muchos trabajadores y me da miedito de que me falten al respeto (entrevista con mujer joven, Valle Real, coto de lujo, 27 de mayo de 2012). 


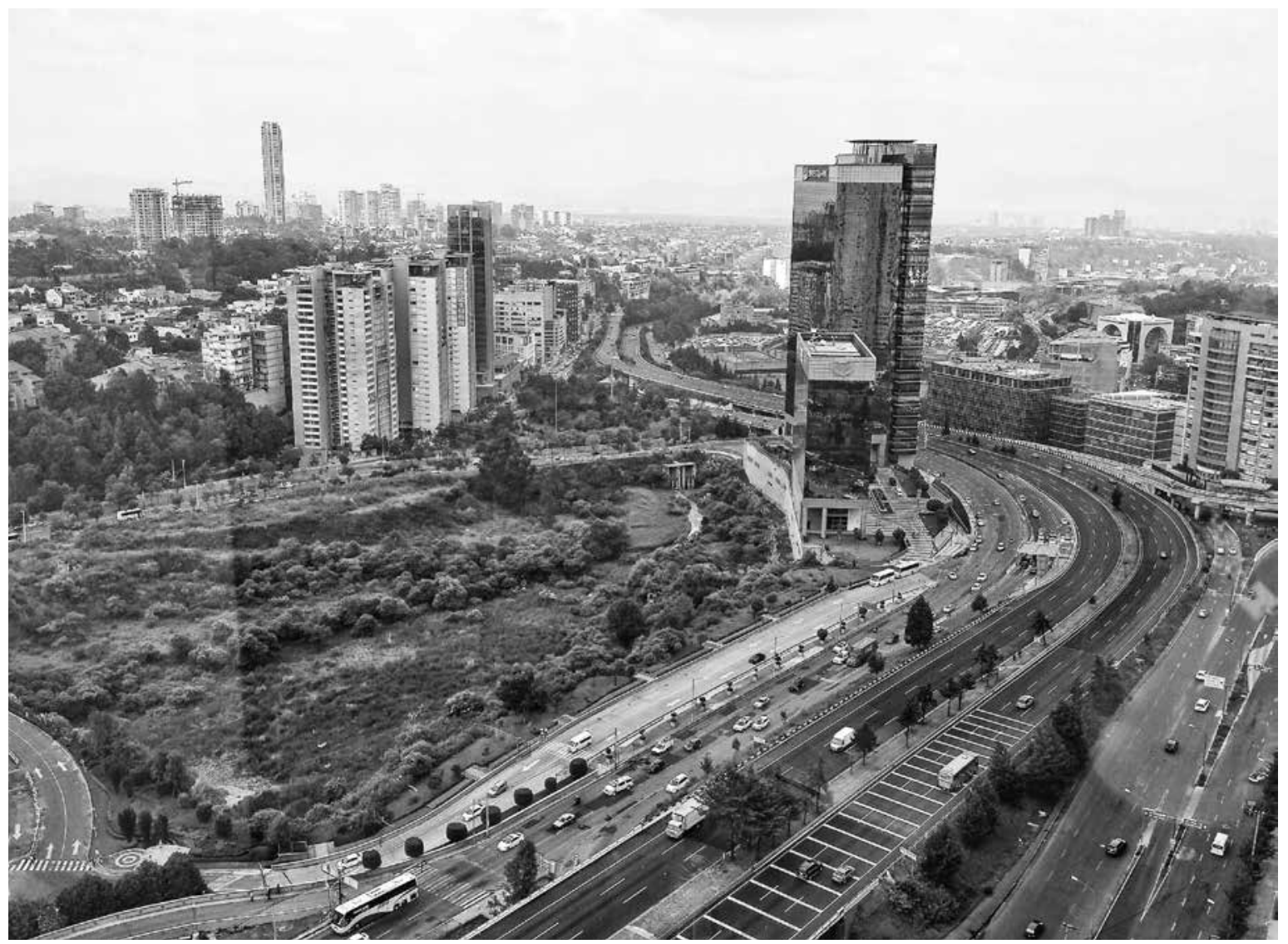

Lucy Nieto • Santa Fe, Ciudad de México, agosto de 2014.

Los habitantes de los cotos sortean así la interacción con lo diverso y lo imprevisible, que sería parte consustancial de la experiencia urbana "típica". 9

Como señalan Duhau y Giglia (2016), el urbanismo insular no es algo nuevo, ya ha habido procesos de elitización en la ocupación de las ciudades, pero ahora los vemos afinados y potenciados con la prioridad que establece la preocupación por "la seguridad". Sus habitantes manifiestan un desasosiego continuo ante los peligros del exterior. Dice Kessler: "parece que la experiencia de la urbanización privada ha configurado una nueva sensibilidad frente a lo inseguro al intensificar o, al menos retroalimentar, la percepción de los riesgos externos" (2009: 245), aunque la fragmentación de la trama urbana no elimina la interdependencia con otros órdenes urbanos, siempre presentes en las ciudades. En Guadalajara no se conforman, como en el Gran Buenos Aires, ciudades apartadas y autosuficientes, aquí hay una mayor cercanía y comunicación de los cotos y sus residentes con otras áreas y habitantes de la metrópolis. El centro histórico de la ciudad está

9

Incluso los "cotificados" reducen el radio de sus movimientos en Guadalajara al establecer unas fronteras simbólicas: las expresiones tradicionales "Oriente pelado" y "Poniente catrín", que se identificaban con la Calzada Independencia, que cruza el centro histórico de la ciudad de norte a sur, ahora se han recorrido a la avenida de Las Américas, más alejada del centro. 
ausente, ya ofrece a los vecinos de estos fraccionamientos mayor atractivo, acuden más como turistas de su propia ciudad que como usuarios ciudadanos:

Al centro jamás voy... Nada más lo que hacemos las mamás es llevar a que los niños se suban alguna vez a la calandria (entrevista con mujer residente, Los Olivos, coto de lujo, 5 de enero de 2010).

Al centro vamos porque vinieron dos chicas de Quebec y las llevamos al centro de turismo a conocer la catedral (entrevista con mujer residente, Bugambilias, coto de lujo, 7 de octubre de 2010).

\section{La neoestamentación y sus implicaciones sociales}

La práctica de los cotos, de crear un mundo a su medida y optar por el apartamiento y el blindaje en su hábitat, evidencia la deserción de ciertos sectores sociales de un ideal de Estado de bienestar y redistribución.

Las dimensiones ideológicas conservadoras del mensaje asociado a la vida de coto incluyen comprenderse en la sociedad por una posición merecida, que puede alcanzarse por medio del trabajo; por la jerarquía, con la subordinación naturalizada de amplias capas populares, y desde la diferencia. Esto nos habla de procesos de rigidez social y de retorno a un orden colonial estamental. Las relaciones estamentales actualizan la propuesta de Weber (1967), como posiciones sociales que grupos sociales y étnicos creerían basadas en privilegios adquiridos porque sí, aunque en este caso se relacionan con patrimonio y acceso al consumo, acaparamiento de recursos y oportunidades. La vida en el coto y el estamento social coinciden en que tienden a ser autocontenidos y endogámicos.

Vemos cómo las relaciones de servidumbre y el estigma de raza, clase y género sobre ciertos sectores se mantienen hasta hoy y se combinan con otras formas de relación social y administración sociopolítica, como el clientelismo corporativo, las relaciones contractuales asalariadas y la flexibilidad laboral creciente, ya que la actual barbarie del mercado se impone y retoma la huella colonial (Pérez, 2014). Estas relaciones resultan funcionales en el contexto contemporáneo, en especial en los fraccionamientos cerrados, como si recuperaran lógicas subyacentes: "estos universos totales y autónomos parecen capaces de realizar las más extrañas fantasías. Una de ellas es el deseo de traer el pasado de vuelta al estilo retro posmoderno" (Caldeira, 2007: 330).

A continuación, argumentaremos esta idea mediante las clasificaciones socioespaciales de los "cotificados" y veremos el reforzamiento de este modelo de vida con los hijos ya socializados en el coto, y por último, con su expansión y réplica en otros sectores sociales.

\section{La banalización de la desigualdad: lo feo versus lo bonito}

Los residentes de los cotos de estatus describen con detalle sus condiciones de vida y las presentan como el modelo de vida deseable. Los entrevistados hacen explícita su posición de privilegio, asumen su situación social e internalizan y propagan el discurso dominante y tópico de su "buen vivir":

La verdad es que estoy en el momento más cómodo en cuanto a la cuestión laboral, el trabajo que tengo en este momento es como el trabajo ideal, porque tengo mis horarios. En la cuestión de vivienda, mi casa me parece hermosa, el condominio donde vivo está padrísimo porque todos somos como muy buenos vecinos, el área me parece muy linda, yo me siento, la verdad, súper cómoda en este momento. Estoy como perfecta, la verdad. Privilegiados, totalmente privilegiados (entrevista con mujer residente, Residencial Azaleas, coto de lujo, 15 de mayo de 2017). 
Nosotros damos una cuota bimestral y con eso se paga todo lo que son parques y jardines, basura, agua, luz, que salió un bache, nos encargamos por el privilegio de tener estas barreritas. Mucho se dice que es ilegal, anticonstitucional, sí lo es, porque las vías públicas pues son vías públicas, en el momento que la municipalidad diga que "se abra", les decimos "pues paga luz, paga basura". Ahí ya es otra cosa. Por eso el municipio como que permite estos privilegios (entrevista con mujer profesionista, Valle Real, coto de lujo, 29 de abril de 2011).

Las mañanas aquí son bellísimas. Todavía ves ardillitas, ves tlacuaches, ves pajaritos, no sé, hay muchas especies muy padres. Es un concepto padrísimo, muy pero muy agradable, yo lo recomiendo completamente a la ciudadanía. Somos privilegiados de poder estar en un lugar como éste. ¡Yo estoy encantado en este fraccionamiento! Realmente es un concepto muy de Guadalajara (entrevista con empresario, Valle Real, coto de lujo, 24 de junio de 2010).

En estos casos, vemos varias referencias respecto al privilegio. En el primero, la mujer habla de sus condiciones de vida con un rosario de calificaciones positivas: cómodo, ideal, hermosa, padrísimo, muy buenos recursos, linda, súper cómoda, perfecta. En el segundo, se mencionan las tensiones con las autoridades municipales y la deslegitimación de éstas con el reemplazo de sus servicios por los autogestionados. En el tercero se habla de la ciudadanía como un ente limitado y exclusivo, como si se tratara de un club, alejado del que correspondería a un orden político democrático e incluyente. Los tres testimonios confirman la identificación del modelo "cultural" del coto y sus moradores con una posición de poder que entienden como legítima y exitosa.

En sus discursos proselitistas, hay palabras que se repiten, como clichés — plusvalía, seguridad, súper a gusto, limpieza, comodidad, tranquilidad, armonía, reglas, concepto del coto y concepto de la vivien$\mathrm{da}-$, en frases como las siguientes:

Aquí hay más seguridad, tranquilidad, no estás escuchando ruidos todo el día, como en otras partes (entrevista con mujer, Jardín Real, coto estándar, 24 de octubre de 2016).

Valle Real es como entrar a otra miniciudad y es como una tranquilidad inmensa, porque entras y ves a todos felices, muchas áreas verdes y así. Además, afuera del fraccionamiento hay demasiado de todo: restaurantes, plazas, cine, gimnasios, tiendas, todo, todo hay (entrevista con estudiante de gestión cultural, Valle Real, coto de lujo, 4 de mayo de 2017).

En los testimonios, y como señala Svampa, "lo primero que sorprende es la literalidad de sus discursos, pues éstos retoman con puntos y comas, los tópicos que divulgan suplementos, publicistas y desarrolladoras" (2008: 88). Patricia Rojas describe impresionada los espacios impolutos de la urbanización Nordelta, en el Gran Buenos Aires:

Fue la sensación de caminar por un mundo distinto. Aquí no hay semáforos. No hay pobres. No hay veredas. No hay rejas. No hay hospitales. Las calles doblan y toman las formas de las lomas que sortean o hay calles sin salida, sólo hechas para girar (cul de sac). Los jardines tienen flores exóticas: no hay claveles ni margaritas. No hay perros sueltos. No hay ropa tendida. No hay basura en los cordones ni tampoco hojas caídas de los árboles. Los colores de las casas se parecen. Los adoquines de los porches también... Es como si alguien hubiera barajado y repartido otras cartas para inventar un nuevo mundo sin las incertidumbres del anterior (2007: 23).

En las colonias de la periferia se produce la estigmatización territorial. Un determinado espacio se 
reduce a ciertos atributos negativos estereotipados que lo desacreditan en términos sociales (Kessler y Dimarco, 2013). Encontramos entonces una construcción social de guetos forzosos. ${ }^{10}$ El estigma hacia sus habitantes los inhabilita en su ciudadanía por su pertenencia espacial, lo que genera una desmoralización colectiva que socava sus acciones y cohesión social (Foust, 2015; Wacquant, 2010). Esto parece justificar su desposesión, sus empleos precarios, el transporte insuficiente y de calidad ínfima, su relegación en las políticas sociales y la ausencia de servicios oficiales, su marginalidad y los altos niveles de violencia. Cristina Bayón añade: "las características 'culturales' de los sectores pobres tienden a ser causalmente fusionadas con las características económicas de la pobreza" y ellos mismos llegan a asumirse como flojos, dejados, viciosos, lo que expone la efectividad de la violencia simbólica (2012: 149; 2015).

Los contrastes en los espacios que habitan estos dos grupos polares son fuertes. Los entrevistados expresan la desigualdad con la exposición de lo feo, lo pobre, lo desordenado versus lo bonito, lo limpio, lo rico, lo bien, lo ordenado, y con connotaciones raciales, lo oscuro frente a lo blanco:

Fuera del coto de Las Palomas el ambiente era medio feo, era zona clase baja (entrevista con mujer joven que salió de coto y lo extraña, 31 de octubre de 2016).

Nosotros vivíamos antes en Tabachines [colonia popular], como las primeras cuadras, no es la zona fea de Tabachines. Y la casa estaba bonita, teníamos una casa, pues bien. Pero la zona no es bonita realmente. Ya más atrás sí es muy cholo, diferente [...]. Yo ya saqué una casa. Está por Cañadas [campestre de lujo, cercano a Tabachines]. La zona me gusta. Para vivir está bonito, está tranquilo, está el bosque del Centinela, está muy bonito. O sea, es una zona bonita (entrevista con estudiante universitario, Bugambilias, coto de lujo, 2 de mayo de 2017).
Estas palabras exponen la diferencia y se deslindan de categorías o expresiones más crudas. Así, se despolitizan los referentes, que se comunican como neutros, inocentes y sin compromiso hacia quienes son deslegitimados. ${ }^{11}$ Es una operación de banalización de la desigualdad y de estetización moral: lo bonito-feo estetiza lo bueno-malo. Quienes ejercen esta forma polarizadora y maniquea de entender el mundo social, que oscurece los efectos del poder y la dominación en términos estructurales, incorporan una fuerte violencia simbólica. ${ }^{12}$ De esta manera se impone como evidente, como el bourdieuliano orden de las cosas, el lugar de cada uno en la sociedad como condiciones diferentes, estar bonito o feo, ser privilegiado o desafortunado, no se escoge.

Hoy vemos que se simplifican las categorías de desigualdad hacia los pobres y sus características asociadas, como mala crianza, desintegración familiar, alcoholismo y drogadicción, propensión a la delincuencia y la violencia, incapacidad para educarse y "superarse". En el proceso de "cotificación", se identifica una identidad amenazante que tiende a ser invisibilizada, ignorada y alejada, para legitimar la estratificación y la inequidad en lugar de reconocer o la asimilar la diferencia y la desigualdad (Pérez,

10 En referencia a Chimalhuacán, Bayón señala el cambio actual en la vida barrial: se sale poco, hay un aislamiento en la casa-taller o comercio, contacto nulo con instituciones de cultura y escasa solidaridad (2015: 120).

11 Como expone Bourdieu, "las relaciones lingüísticas siempre son relaciones de fuerza simbólica a través de las cuales las relaciones de fuerza entre los locutores y sus grupos respectivos se actualizan bajo una forma transfigurada" (Bourdieu y Wacquant, 1995: 102).

12 Los pares categoriales - de género, raza, territorio- demarcan fronteras sociales de forma radical y justifican valoraciones y clasificaciones jerárquicas, organizan la experiencia social, institucionalizan la desigualdad y la hacen funcional (Tilly, 2000). Como veremos, lo feo se asocia y articula con otras calificaciones -cholos, drogadictos, delincuentespara reforzar, en nuestro caso, la inferiorización del sector social que se busca contener. 
2014). Con ello se produce la desacreditación e inferiorización social, la criminalización de la pobreza y el reforzamiento de un orden estamental acompañado de una interpretación de la sociedad que obvia las causas y los procesos históricos de desigualdad y violencia.

\section{Los hijos de cotos}

La tendencia hacia el deslinde e incomunicación socioespacial, favorecida por vivir en urbanizaciones cerradas, se profundiza con "los hijos de los cotos" o sujetos socializados en estos contextos, que validan la decisión tomada por sus padres y se inclinan a repetir este modelo de vida en su experiencia con hijos propios. Así, una consecuencia de habitar en coto es que los chicos comparten un escaso conocimiento del mundo social y más bien conocen categorías ocupacionales subalternas, personas a quienes hay que mandar (Svampa, 2008).

Los hijos de esta "burguesía" acuden a colegios y universidades privados en los que se reproducen de manera estratégica las relaciones necesarias para el futuro. Para muchos padres, esto supone un esfuerzo económico, porque se verán obligados a adquirir deudas para hacer fiestas y "tienen que tener la clase de piano, de pintura, talleres y la ropa, porque todas son modelos" (entrevista con mujer ex residente de Valle Real, 17 de noviembre de 2013). Estudian licenciaturas clásicas, como administración de empresas o derecho, o nuevas, como nutrición, diseño, ligadas a tecnologías de la comunicación e informática. Su afán es insertarse con éxito en el valor social de ser un buen ciudadano consumidor. Para Jesús, un joven residente del coto estándar Quintas de La Soberana, sus ejemplos de vida son los protagonistas de las películas El lobo de Wall Street y El gran Gatsby; sueña con vivir "en un coto, como aquí en El Palomar. Sobre todo, es que, pues es que hay dinero, hay abundancia" (citado en Unda, 2011: 21).
Paulo Unda cita a Luis, quien decidió estudiar la carrera en la Universidad de Guadalajara y conoció ahí una realidad aparte:

Yo estaba acostumbrado a tener amigos que sus papás son dueños de empresas transnacionales y que viven en Colinas de San Javier, Puerta de Hierro o Valle Real. Todos con negocio propio o gerentes generales de empresas, y acá en la UdeG, pues mis compañeros eran mecánicos, carpinteros, de todo, hasta lavacoches o miembros de alguna empresa de seguridad privada. Fue un choque muy grueso de cultura. Más que nada, me aterrizó en la ideología de que el dinero no lo es todo (2011: 17).

Estas experiencias socioculturales no han supuesto una modificación del estilo de vida de Luis, más bien confirmaron su privilegio:

Nos volvimos a apartar... Ése era nuestro lugar de encuentro, la universidad. Y ya otra vez volvimos a darnos cuenta que tenemos vidas muy diferentes. Ahora que estoy trabajando ya puedo viajar de una manera más cómoda o a hoteles de mayor prestigio, o a zonas turísticas de mayor prestigio o más bonitas o más caras simplemente, eso es finalmente lo que ya nos separó (Unda, 2011: 18).

Estudiar en esa universidad le sirvió para reforzar los mismos valores, creencias y convicciones que le fueron inculcados. Al cabo, "al lujo se acostumbra uno fácil”, como decía una mujer francesa procedente de un barrio popular parisino, casada con un ejecutivo de empresa transnacional, lo que le permitió pertenecer al coto campestre Rancho Contento.

Estas aspiraciones a la vida cómoda son recurrentes. Una estudiante de preparatoria en un colegio de elite expresa: "yo quiero ser doña Voyager: señora de coto. Yo me voy a casar con un rico que 
me tenga en un gimnasio". ${ }^{13} \mathrm{O}$ esta joven de Valle Real, entrevistada por una alumna:

Si llego a tener familia, me encantaría [seguir aquí]. Es como el lugar ideal para vivir en familia. Por el momento no planeo irme a vivir sola, aquí hay demasiadas comodidades, de mensa me voy. Quizá después me gustaría vivir en un depa, ya que termine de estudiar y esté trabajando en lo que me gusta, que me deje lana (entrevista con estudiante de gestión cultural, Valle Real, coto de lujo, 4 de mayo de 2017).

El mismo Luis exhibe su visión estigmatizante de la sociedad:

A mí me gustaría que mis hijos crecieran en un ambiente seguro. En donde las prácticas de la calle no sean drogarse o andar haciendo cosas que no deben hacerse, cosas que van contra la ley. Más bien me gustaría un lugar bonito, con gente agradable, educada. Que el hijo de la vecina no sea el que roba tienditas o el que consume thinner (Unda, 2011: 22).

\section{El efecto vitrina}

El modelo de condominio cerrado ha sido exitoso y las urbanizadoras han sabido imponerlo en todas las capas sociales por medio del horizonte aspiracional, su asociación con el poder del mercado y el consumo, y la ilusión del derecho individual a escoger. Las elites, que hegemonizan ideologías, discursos y representaciones al jugar como guías civilizatorias hacia el resto social, funcionan como una vitrina cultural. Me refiero a la reproducción de la forma de vida y comportamientos del condominio en otros sectores sociales.

Antes de abundar en este punto, quiero exponer que hay una forma de vida extendida entre los sectores medios altos y altos de Guadalajara, más allá del vivir en un coto. Muchos residentes de la ciudad presumen de no vivir en coto ni compartir sus esfuerzos de distinción pues les parece "naco". Este adjetivo desvalorizante se produce porque el modelo de condominio exige normas de convivencia colectiva que no se aplican a propietarios "clásicos" individuales. Con estas reglas se pierde autonomía y poder de decisión, lo que se entiende como sometimiento a un colectivo. También se señalan las similitudes del coto con el vivir en una vecindad, es decir, en mayor dependencia con los vecinos. El régimen de condominio es la dificultad más grande para los habitantes de estos residenciales, pues hay poca experiencia de compartir con otros las normas de su propio hábitat.

Sin embargo, las implicaciones de este modelo de vida son más compartidas de lo que pensamos: todos viven en casas blindadas en la llamada calle abierta, pasan buena parte de su tiempo en centros comerciales, llevan a sus hijos a la escuelas privadas y bilingües, gozan de seguros de salud, transitan en auto por la misma cartografía limitada, no saben del transporte público, disfrutan de servidumbre, son miembros de clubes, quieren verse jóvenes y "a gusto", y su ideal llevado a la práctica es tener una familia "como la de siempre". Comparten más de lo que creen, en particular su condición de privilegio y el aislamiento social.

Sobre el efecto vitrina, hay que señalar que los cotos paradigmáticos son residenciales suburbanos de elite, pero vemos calles que se privatizan, pequeños cotos que brotan en los centros urbanos, fraccionamientos de clases medias que se autocalifican como vecindades con más estatus. Cuando esto ocurre, la aplicación del modelo encuentra fuertes distorsiones. Las condiciones y prácticas dentro de cotos de

13

Conversación con un psicólogo en la preparatoria, 23 de abril de 2013. 


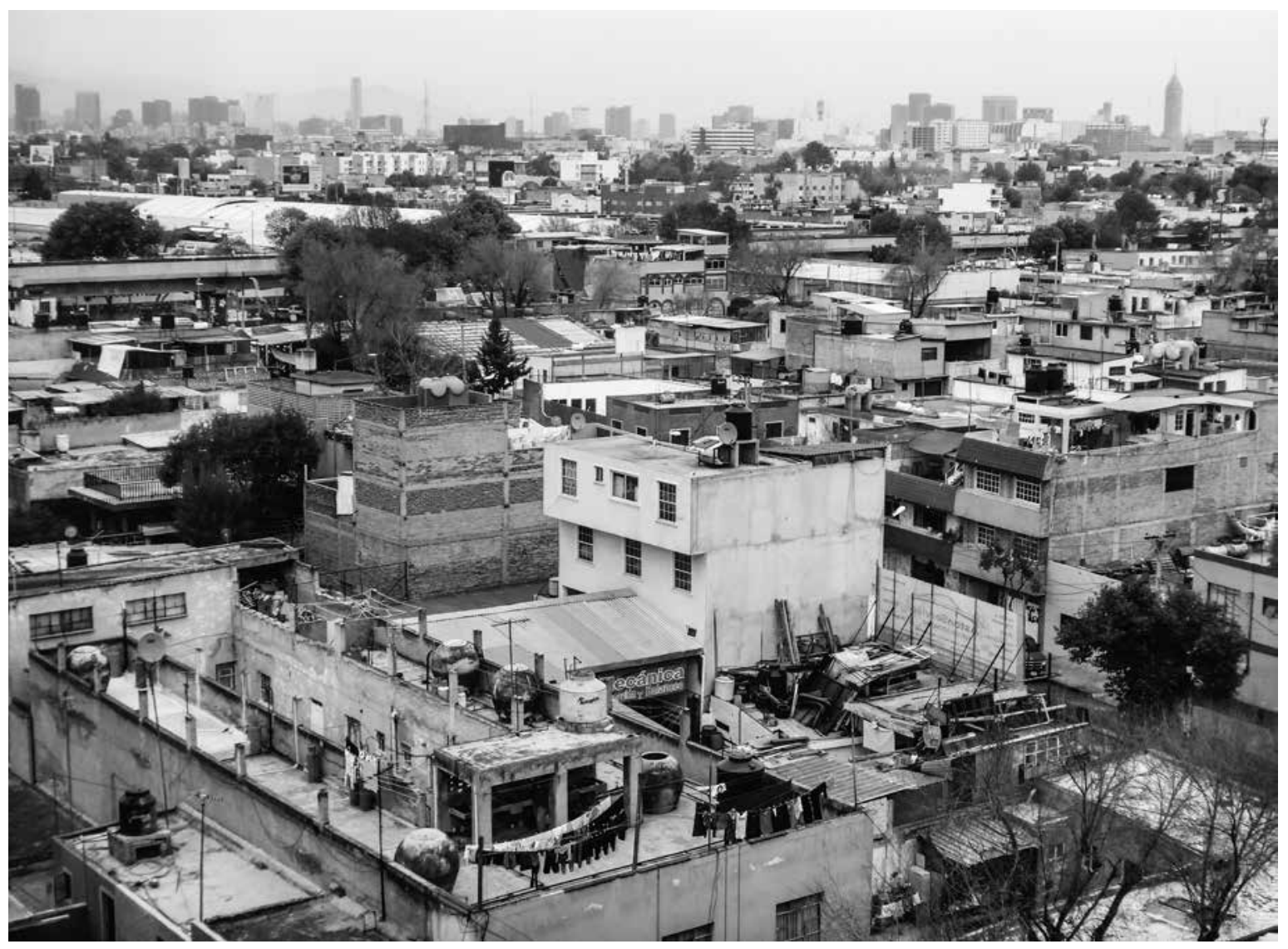

Lucy Nieto • Colonia Asturias, Ciudad de México, enero de 2013.

otro nivel socioeconómico suponen una convivencia más difícil por la falta de espacio y los problemas económicos que pueda haber en los hogares. Hay diferencias y desigualdades en todos los sentidos, son dificultades: el acceso a consumo y mercado; la tenencia del coche y su estacionamiento; la calidad de los servicios de seguridad; el funcionamiento de un orden de servidumbre; la falta de disposición de espacios y comodidades, como jardines y terrazas; el pago irregular de las cuotas.

Éstos son los límites de un ideal comunitario en un contexto de precariedad permanente, de competencia social en un mundo con menos opciones. Igual que en los cotos de lujo, se complementa con la desazón por el estatus/mercado, la imitación y aspiración por las formas y privilegios de las "clases vitrina”, que se dibujan en su imaginario. Un residente del coto medio El Pueblito, que vivía en un barrio popular, dice: "no estás que pasa la gente y te pide dinero, que no sabes ni qué, te evitas muchos problemas, por eso me encierro, procuro traer todo antes de llegar a la casa y no andar saliendo" (entrevista, 8 de noviembre de 2016). Esto nos dibuja un ambiente de guerra y toque de queda normalizado en la cotidianidad.

También hay casos como el de don Chava, en el residencial Versalles Urbi Quinta, en el municipio de Tonalá. Él es un arribista, que explica satisfecho su posición y un discurso de poder clasista y exclusivo que busca transmitir de manera activa. 
Con 55 años de edad, es casado y tiene tres hijos, es dueño de un gimnasio, tiene una licenciatura en nutrición y cultura física y deportes. Se mudó aquí hace dos años, es propietario de tres casas y su estacionamiento cuenta con cinco plazas:

El cuarto de mi hijo parece recámara de hotel de lujo, tiene su propio clóset súper gigante, que cualquier niña quisiera tener, si ves su cuarto te mueres de la envidia, te lo juro. Además, desde que vivimos aquí, su visión de vida cambió, aunque me cueste muy caro, vale la pena porque sé que es súper exigente con todo, su forma de vestir siempre tiene que ser de lo bueno, todo tiene de marcas y así. Prefiero que tenga esas visiones y que quiera ser alguien de bien, a andar viéndolo en el desmadre, así que considero que sí, el fraccionamiento te exige a ser mejor persona, y a tener ideales de superación.

Estar en este fraccionamiento nos ha permitido escalar hacia arriba, ahora vivimos en un mejor lugar y nuestras vidas se han mejorado. Tenemos la visión del fraccionamiento que nada que ver en México, ahí no tenemos ningún tipo de contaminación, no ves contaminación visual ni auditiva, ni nada. Es una utopía.

El fraccionamiento es privado, todo está muy restringido, y algo así estábamos buscando. La calidad de todo el coto va en alza, tenemos nuestros propios parques, además tenemos una vista que da hacia la barranca, es un pequeño lujo que casi nadie tiene, pero te aseguro que todos quisieran tener. $Y$ es totalmente seguro, esto es debido a que todos correspondemos a un estatus económico igual o muy parecido, y una misma visión de mundo, entonces nadie tenemos la necesidad de tomar lo de los demás, cada quien tiene sus lujos y respeta a los de al lado. Si algo se perdiera te aseguro que votaríamos para que se pusieran cámaras.
Yo no regresaría a una vivienda, para empezar ya no me gusta la ciudad, aquí estamos apartados de todo y tenemos una tranquilidad total, ya no podría vivir con vecinos que no tienen un mismo tipo de vida. Aquí no hay robos ni envidias, no tenemos que lidiar con las vecinas chismosas que sólo están viendo qué hace el de al lado. ¡Imagínate vivir donde hay cholos y el tráfico! ¡No, pero qué feo! Ya no me sentiría cómodo estando en un lugar tan inseguro (entrevista con don Chava, Residencial Versalles Urbi Quinta, 12 de octubre de 2016).

Los cotos se han instalado con firmeza en las ciudades mexicanas, como hemos visto en Guadalajara. Sus habitantes ofrecen y promocionan una representación-realidad de autosegregación y deslinde de responsabilidad social hacia el resto de los ciudadanos metropolitanos, pero también de éxito: ¿quién no desearía vivir en Versalles?

Frente a las ansiedades generadas por la inseguridad, la violencia, la corrupción, el desorden y la incertidumbre, el discurso, la representación y la práctica del privilegio son firmes, claros y estereotipados, pero funcionan y se hacen deseables para la población al encarnar valores entendidos como positivos. El discurso también está cargado de violencia simbólica por el sistema clasificatorio en jerarquías y el trasfondo moral que impone al destilar la complejidad social en la consideración de lo bonito y lo feo.

Los fraccionamientos cerrados y el hecho de habitar el privilegio se posicionan ante el declive del Estado de bienestar y las utopías sociales de igualdad, y se erigen como símbolos de poder y superioridad gracias a la capacidad demostrativa de las elites - y de quienes aspiran a serlo- no sólo en términos económicos sino simbólicos y culturales. Llama la atención cómo se reposicionan y hasta "democratizan"; la ideología elitista y la "cristalización de las grandes asimetrías" extramuros se extienden.

Es preciso indagar más en la enorme capacidad de las elites de mantener sus privilegios y que ello 
nos parezca natural. Esto requiere dejar de considerarlas intocables en los análisis de las ciencias sociales para dirigir la mirada hacia ellas, retomar el análisis de clase y afinar la exposición de las consecuencias de los sistemas clasificatorios y las formas de valor, juicios y normas que se establecen en la sociedad, como defiende Tyler (2015).

\section{Bibliografía}

Arizaga, María Cecilia, 2005, El mito de la comunidad en la ciudad mundializada: estilos de vida y nuevas clases medias en urbanizaciones cerradas, El Cielo por Asalto, Buenos Aires.

Bauman, Zygmunt, 2008, Comunidad. En busca de seguridad en un mundo hostil, Siglo XXI Editores, Madrid.

Bayón, María Cristina, 2012, "El 'lugar' de los pobres: espacio, representaciones sociales y estigmas en la ciudad de México", en Revista Mexicana de Sociología, vol. 74, núm. 1, pp. 133-166.

—_, 2015, La integración excluyente. Experiencias, discursos y representaciones de la pobreza urbana en México, Universidad Nacional Autónoma de México-Instituto de Investigaciones Sociales/Bonilla Artigas Editores, México.

Botton, Alain de, 2004, Ansiedad por el estatus, Taurus, Bogotá.

Bourdieu, Pierre, 2002, La distinción. Criterio y bases sociales del gusto, Taurus, México.

Bourdieu, Pierre y Loïc Wacquant, 1995, Respuestas por una antropología reflexiva, Grijalbo, México.

Cabrales Barajas, Luis Felipe y Elia Canosa Zamora, 2002, "Nuevas formas y viejos valores: urbanizaciones cerradas de lujo en Guadalajara", en Luis Felipe Cabrales Barajas (coord.), Latinoamérica: países abiertos, ciudades cerradas, Universidad de Guadalajara/Organización de las Naciones Unidas para la Educación, la Ciencia y la Cultura, Guadalajara, pp. 93-116.

Caldeira, Teresa Pires do Rio, 2007, Ciudad de muros, Gedisa, Barcelona.

Camus, Manuela, 2015, Vivir en el coto. Condominios cerrados, mujeres y colonialidad, Universidad de Guadalajara, Guadalajara.

Camus, Manuela y María Eugenia de la O, 2014, "El discreto encanto de la colonialidad tapatía. Notas sobre la cultura de servidumbre", en Séverine Durin, María Eugenia de la O y Santiago Bastos (coords.), Trabajadoras en la sombra. Dimensiones del servicio doméstico latinoamericano, Centro de Investigaciones y Estudios Superiores en Antropología Social/Escuela de Gobierno y Transformación Pública/Tecnológico de Monterrey, México, pp. 145-171.

Duhau, Emilio y Ángela Giglia, 2008, Las reglas del desorden: habitar la metrópoli, Siglo XXI Editores/Universidad Autónoma MetropolitanaAzcapotzalco, México.

, 2016, Metrópoli, espacio público y consumo, Fondo de Cultura Económica, México.

Durin, Séverine, 2017, Yo trabajo en casa. Trabajo del hogar de planta, género y etnicidad en Monterrey, Centro de Investigaciones y Estudios Superiores en Antropología Social, México.

Enríquez Acosta, José Ángel, 2007, “Ciudad de muros. Socialización y tipología de las urbanizaciones cerradas en Tijuana”, en Frontera Norte, vol. 19, núm. 38, pp. 127-156.

Foust, David, 2015, Sentimiento de inseguridad, estigmatización territorial y eficacia colectiva en dos colonias de la periferia metropolitana de Guadalajara, tesis de doctorado en ciencias sociales, Universidad de Guadalajara, México.

Janoschka, Michael y Georg Glasze, 2003, “Urbanizaciones cerradas: un modelo analítico”, en Ciudades, núm. 59, pp. 9-20.

Kessler, Gabriel, 2009, El sentimiento de inseguridad. Sociología del temor al delito, Siglo XXI Editores, Buenos Aires.

Kessler, Gabriel y Sabina Dimarco, 2013, “Jóvenes, policía y estigmatización territorial en la periferia de Buenos Aires”, en Espacio Abierto, vol. 22, núm. 2, pp. 221-243.

Low, Setha, 2003, Behind the Gates: Life, Security, and the Pursuit of Happiness in Fortress America, Routledge, Nueva York.

Pérez Sáinz, Juan Pablo, 2014, Mercado y bárbaros. La persistencia de las desigualdades de excedente en América Latina, Facultad Latinoamericana de Ciencias Sociales-Costa Rica, San José.

Ray, Raka y Seemin Qayum, 2009, Cultures of Servitude. Modernity, Domesticity, and Class in India, Stanford University Press, Stanford. Rojas, Patricia, 2007, Mundo privado. Historias de vida en countries, barrios y ciudades cerradas, Planeta/Seix Barral, Buenos Aires. 
Safa Barraza, Patricia y Juan Manuel Ramírez Sáiz, 2011, "Deterioro urbano y calidad de vida en las grandes urbes: la participación de las mujeres en las organizaciones vecinales”, en La Ventana, vol. 4. núm. 34, pp. 110-145.

Shore, Cris, 2002, "Introduction: Towards an Anthropology of Elites", en Cris Shore y Stephen Nugent (eds.), Elite Cultures. Anthropological Perspectives, Rouledge (ASA Monographs 38), Londres, pp. 1-21.

Svampa, Maristella, 2008, Los que ganaron. La vida en los countries y barrios privados, Biblos, Buenos Aires.

Tilly, Charles, 2000, La desigualdad persistente, Manantial, Buenos Aires.

Tyler, Imogen, 2015, "Classificatory Struggles: Class, Culture and Inequality in Neoliberal Times”, en The Sociological Review, vol. 63, núm. 2, pp. 493-511.

Unda Gutiérrez, Paulo César, 2011, La vida en los cotos, versión mimeografiada de tesis de licenciatura en sociología, Universidad de Guadalajara, México.

Wacquant, Löic, 2010, Las dos caras de un gueto. Ensayos sobre marginalización y penalización, Siglo XXI Editores, Buenos Aires.

Weber, Max, 1967, Economía y sociedad, Fondo de Cultura Económica, México.

\section{Entrevistas}

Arquitecta, Ciudad Granja, coto estándar, 5 de enero de 2010.

Don Chava, Residencial Versalles Urbi Quinta, 12 de octubre de 2016.

Empresario, Valle Real, coto de lujo, 24 de junio de 2010.

Estudiante de gestión cultural, Valle Real, coto de lujo, 4 de mayo de 2017.

Estudiante universitario, Bugambilias, coto de lujo, 2 de mayo de 2017.

Gestora de bienes raíces, Valle Real, coto de lujo, 13 de marzo de 2011.

Mujer, Bugambilias, coto de lujo, 7 de octubre de 2010.

Mujer, Jardín Real, coto estándar, 24 de octubre de 2016.

Mujer, Los Olivos, coto de lujo, 5 de enero de 2010.

Mujer, Residencial Azaleas, coto de lujo, 15 de mayo de 2017.

Mujer, Valle Real, coto de lujo, 12 de mayo de 2011.

Mujer artista, Valle Real, coto de lujo, 13 de abril de 2011.

Mujer estudiante, Villa Coral, coto estándar, 3 de mayo de 2017.

Mujer ex residente de Valle Real, coto de lujo, 17 de noviembre de 2013.

Mujer joven que salió de coto y lo extraña, 31 de octubre de 2016.

Mujer joven, Valle Real, coto de lujo, 27 de mayo de 2012.

Mujer joven, Quintas de La Soberana, coto estándar, 2 de mayo de 2017.

Mujer jubilada, Bugambilias, coto de lujo, 27 de abril de 2017.

Mujer profesionista, Valle Real, coto de lujo, 29 de abril de 2011.

Pequeña empresaria, Rancho Contento, coto campestre, 21 de agosto de 2012.

Residente, El Pueblito, coto medio, 8 de noviembre de 2016

Susi, trabajadora autónoma, Rancho Contento, coto campestre, 5 de julio de 2012. 